\title{
Association Rules Analysis between Brand Post Characteristics and Consumer Engagement on Social Media
}

\author{
Zhijie Zhao $^{1,2}$, Yang Liu ${ }^{1,2, *}$, Jiaying Wang ${ }^{1,2}$, Biao Wang $^{3}$, Yiqi Guo ${ }^{1,2}$ \\ ${ }^{1}$ School of Computer and Information Engineering, Harbin University of Commerce \\ No.1 Xuehai str. Songbei District, Harbin 150028, China \\ E-mail.zhaozj@hrbcu.edu.cn; 1249182744@qq.com (Correspondingauthor*); wangjiaying@uzz.edu.cn; \\ 929926551@qq.com
}

${ }^{2}$ Heilongjiang Provincial Key Laboratory of Electronic Commerce and Information Processing No.1 Xuehai str. Songbei District, Harbin 150028, China

${ }^{3}$ School of Business, Harbin University of Commerce

No.1 Xuehai str. Songbei District, Harbin 150028, China

E-mail.wangb@hrbcu.edu.cn

cross $^{\text {ref }}$ http://dx.doi.org/10.5755/j01.ee.32.4.28060

Brands are increasingly using social media to create and manage posts to initiate and maintain consumer engagement. Based on the theory of consumer engagement, a perspective of brand post content, form and posting time is introduced to construct a conceptual model of consumer engagement for Sina Weibo. Rough set method and reduction algorithm of Holte $1 R$ are used to automatically generate the optimal decision rules. Rough set method does not need any prior knowledge and assumptions, which could effectively overcome the disadvantages of traditional statistical methods. The results show that entertainment content is easy to trigger moderate level of consumer engagement, the effect of information content on shares is significantly stronger than that of comments and likes, and the promotion content has an impact on liking. As the most vivid and the most interactive characteristic respectively, videos and questions significantly affect the mid-level consumer engagement. Keeping post length in the range of 16-50 characters stimulates the medium degree of sharing. Posts created on weekend promote the medium level of sharing and the low level of liking, while published at the peak or low peak period trigger the same level of sharing, but do not affect comments or likes. The study detects the characteristics that affect consumer engagement and define the scope of its role. The relationship and intensity of different characteristics on different levels of consumer engagement are effectively evaluated and identified by refining the association rules of consumer engagement, which are available for providing reference for brand managers to formulate social media marketing strategies.

Keywords: Consumer Engagement; Brand Post Characteristics; Association Rule Analysis; Rough Set Method; Social Media.

\section{Introduction}

Social media is seen as an emerging channel for interaction between brands and consumers (Khobzi et al., 2018). Many consumers connect to the internet through social media and smartphone to interact with brands or other consumers in a more diversified way. It has been reported that the monthly active users of social media in the world exceeds 3 billion (Statista, 2019), and more than $50 \%$ of platform users pay attention to brand pages to obtain information (Ismail, 2017). However, such a large user base may be a disaster for brands that do not pay enough attention to word-of-mouth from consumers (Gensler et al., 2013). The dominance of consumers on social media urgently requires brands to understand consumers' changing online interactions and content consumption habits by means of consumer engagement to establish close contact with consumers and then achieve positive business outcomes such as creating corporate sales (Goh et al., 2013), improving financial performance (Rishika et al., 2013), and expanding development and innovation (Dong \& Wu, 2015). Consequently, it is crucial for brands to understand how to attract consumers to engage on social media (De Vries et al., 2014).

Some scholars try to find a breakthrough from brand posts themselves to explore the reasons why consumers engage in social media (Menon et al., 2019). The results show that different brand post characteristics, such as content and vividness, motivate consumers to engage. It is worth noting that there are differences in the introduction and analysis of consumer engagement models in the literature. Sabate et al. (2014) emphasized how post richness and time frame affect consumer engagement. Menon et al. (2019) considered the effect of post content and design on consumer engagement. To cover as many brand post characteristics as possible, the paper constructs a conceptual model of consumer engagement by combining the actual context of brand building posts and introducing a new perspective of post form on the basis of post content and posting time.

At present, traditional statistical methods are used to study consumer engagement, which usually assume that the data reflect a normal distribution and have a linear relationship to provide meaningful inferences. Although it 
reveals the effect of some characteristics, more objective and efficient methods should be considered in the research of brand post characteristics and consumer engagement. The rough set (RS), as an intelligent method based on set theory to deal with uncertain information can effectively analyse historical data without any prior knowledge or assumptions. Existing studies have taken RS as the core technology to conduct empirical studies on location decision improvement (Chen et al., 2016), sentiment classification of product reviews on social media (Asghar et al., 2017), optimization and prediction of consumer satisfaction (Stelios et al., 2018).

In the era of social media with huge amounts of information, the clues consumers rely on for information processing or decision-making are uncertain. RS takes into account the uncertain background of consumer engagement in decision-making, which could detect the series of characteristics that affect engagement more efficiently. To analyse the relationship between brand post characteristics and consumer engagement, the decision rules of consumer engagement that are easily understood are obtained and hidden facts in data are found through the automatic rule generation system. RS can also define the effect strength of different brand post characteristics on consumer engagement by dividing the degree of consumer engagement to enhance the explanatory power. The research is helpful to clarify consumers' content consumption preferences and improve the understanding and cognition of consumer engagement.

The purpose of this paper is to explore the relationship and intensity of different brand post characteristics on consumer engagement. Based on the theory of consumer engagement, consumer engagement on social media is empirically studied from the perspectives of content (entertainment, information, promotion), form (vividness, interactivity, length) and posting time (day of the week, called DOW for short, and peak hour). To ensure the diversity of the cultural environment, data are collected from the official brand pages of brands on Sina Weibo, an influential social media platform in China. Consumer engagement (shares, comments and likes) is divided into three levels: high, medium and low. RS is used as the basic means of modelling, and the algorithm of Holte $1 \mathrm{R}$ is selected for reduction to automatically generate the optimal characteristic decision rule set. The results show that the effects and intensity of brand post characteristics of Sina Weibo on consumer engagement at different levels are different. As far as it is known, this paper is one of the first studies to use the RS method to intelligently capture the relationship between characteristics and consumer engagement, which not only expands the knowledge about the characteristics of promoting consumer engagement, but also provides a reference for brand management and the formulation of social media marketing strategies.

The paper continues with the following structure: Section 2 introduces the background, theory and related literature review. Section 3 puts forward the conceptual framework and research hypothesis. Section 4 shows the data, variables and research methods. Section 5 gives the empirical research results. Section 6 explains the results and discusses the management significance. Section 7 summarizes this paper, explains the contribution and limitations, and provides suggestions for further research.

\section{Related Work}

\section{Brand Page and Post}

Many brands use social media to build brand pages that maintain and connect consumers as a new marketing strategy (Morra et al., 2018). Brand pages are special accounts created and managed by brands (Habibi et al., 2014) that publish relevant information on brands, products, services and activities in the form of brand posts and then construct interactive relationships with consumers. The information communication mode not only reduces the implementation cost of marketing and provides a more flourishing social and marketing communication network for brands (Habibi et al., 2014), but also provides an appropriate environment for consumers to find information, express consumption experience or brand views (Shi et al., 2014).

Unlike user profiles commonly used for personal and social purposes, brand pages and posts are public. It is visible not only to consumers, but also to any random users who use social media, which effectively promotes brands to attract existing and potential consumers (Khobzi et al., 2018). Consumers who follow or use brand pages can also interact with brands or other users through sharing, commenting or liking (Zhang et al., 2017). Brand pages and posts are created by both brands and consumers, which strongly reflects and broadens the relationship between them. The strengthening of the relationship will eventually become an effective predictor of consumers' real purchasing behaviour (Jeon et al., 2015). Therefore, it is becoming increasingly important to study the relationship and intensity of different brand post characteristics on consumer engagement through social media brand pages and posts.

\section{Consumer Engagement on Social Media}

Consumer engagement aims to study the cognition, emotion and behaviour of consumers when they interact/engage with brands/services (Hollebeek et al., 2014; Dolan et al., 2019). Consumer engagement in the context of social media is the psychological state generated by the interactive experience with a focus brand or other consumers (Brodie et al., 2013). At present, the behaviour of consumers is not only the simple purchase behaviour, but also a behaviour pattern with social media as the focus caused by motivation driving factors (Dolan et al., 2016). Therefore, the paper holds that consumer engagement is a multidimensional structure with cognitive, emotional and behavioural dimensions, in which cognition and emotion are the intrinsic psychological motivations that drive consumers to engage in social media, while sharing, commenting and liking are the external behaviours of consumers who take part in social media.

In the process of consumer engagement, brands enhance consumers' loyalty (Busalim et al., 2019), strengthen consumers' purchase intention (Beukeboom et al., 2015), and improve enterprise performance (Rishika et al., 2013) by influencing consumers' brand experience and feelings to improve the efficiency and effectiveness of brand marketing. 
Therefore, it is a valuable goal to grasp the characteristics that enhance consumer engagement on social media.

To achieve this goal, some studies have identified the reasons why consumers engage in social media. Part of the reason is information seeking and trying to use the acquired information to reduce misunderstanding and uncertainty (Azar et al., 2016). Hedonism (Shi et al., 2016) and social psychology (Kang et al., 2014) are also effective characteristics for predicting consumer engagement. The key role of value consistency in consumer engagement is also proposed (Islam et al., 2018). Other studies focus on specific brand post characteristics and explore the relationship between them and consumer engagement (Trefzger et al., 2016).

Recently, academic research on consumer engagement in social media has increased (Lee et al., 2018), but most of them are modelled using traditional statistical methods. Few studies attempt to use data intelligence to explain the relationship between some characteristics and consumer engagement more objectively. In the era of social media with huge amounts of information, the clues consumers rely on for information processing or decision-making are uncertain. As a mathematical tool of uncertain information analysis and processing based on set theory, RS effectively describes the uncertain background of consumer engagement in decision-making. According to brand post characteristics, the association rules of consumer engagement are generated, and the hidden knowledge expression or learning induction is extracted (Pawlak et al., 1995). The application of RS in social media consumer engagement not only checks the usage of brand post characteristics, but also determines the credibility and credibility level of different brand post characteristics that stimulate consumer engagement to improve the understanding and cognition of consumer engagement. In addition, the association rules generated by RS are easy for brand managers to understand and explain.

\section{Conceptual Framework and Hypothesis}

As a part of consumer engagement, brands mainly consider three basic dimensions when publishing posts. First, what content should brand managers issue on the brand page to attract consumers to engage? Second, in what form should brand managers release to trigger more engagement? Third, when should brand managers post?

With regard to the content of brand posts, this paper refers to the existing research results on engagement motivation in brand communities or social networks, and considers the effects of different content types on consumer engagement, such as entertaining, informative and promotional content. The brand post form is divided into two sections. On the one hand, it refers to the media type of the post, and for this purpose, the related concepts of vividness and interaction are cited. On the other hand, it refers to the length of the post. Therefore, this paper focuses on the relevant content in the field of information and advertising to study consumers' response to different forms of content. Finally, to explore the effect of posting time, a potential characteristic, on consumer engagement, this paper discusses two variants of DOW and peak hour based on research on social network usage and online advertising scheduling. Figure 1 illustrates these relations.

\section{Like 、Comment and Share}

The interaction of social media brand pages and posts is mainly brand and consumer, not communication between consumers. When consumers obtain brand-related external segment information through the brand page, they will have the overall perception of the brand function, name and its meaning, and form the cognition of the brand (Bruhn et al., 2013). The process of long-term contact between consumers and brands is similar to the relationship between people (Susan, 1998), in which consumers tend to have rich emotional connections with brands that meet their own needs, and form a positive attitude towards brands. The different levels of cognitive and emotional input from consumers lead to different forms of engagement in social media brand posts (Swani et al., 2020). Therefore, the interaction behaviour of consumers such as sharing, commenting and liking under each brand post is a direct manifestation of consumer engagement, reflects the positive degree of interaction between consumers and brands, and is also a powerful indicator to determine the quality of communication content released by brands.

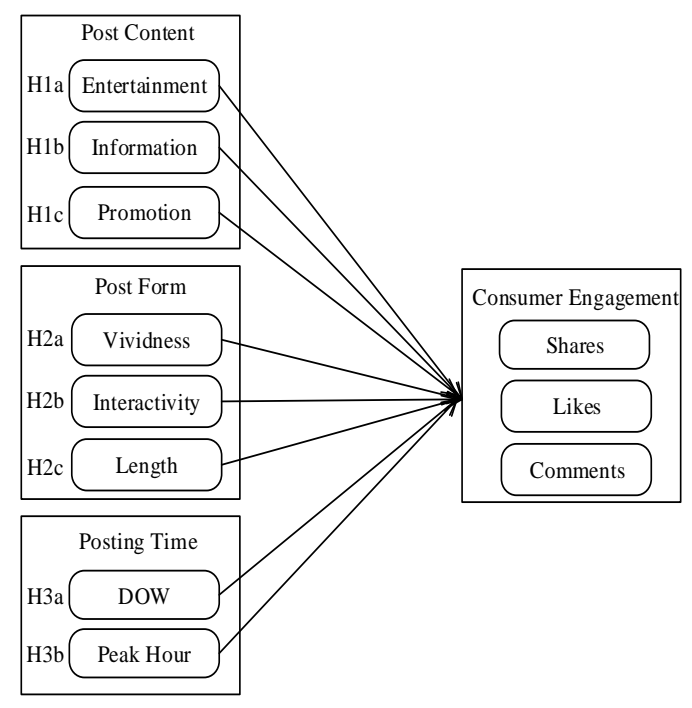

Figure 1. Conceptual Framework for Consumer Engagement

Like is realized by clicking the "like" button. Although it only takes less time or energy, it is a positive evaluation of brand posts, which expresses the attention and positive emotional state of brand posts (Kim \& Yang, 2017). When consumers view a brand post, they take positive, neutral or negative positions and then create comments in a limited brand environment (Gavilanes et al., 2018). This process requires more time, energy and stronger cognitive processing. The behaviour of sharing expresses a positive attitude towards the recommended content, which is equivalent to a clear positive statement. Consumers can use the text to express their opinions and supplement the content to be shared. Not only does sharing play a powerful role in spreading posts, but the information from or filtered by third parties is often considered more reliable and credible (Delerue et al., 2013). When interacting with brand posts by 
sharing, commenting or liking, consumers' cognitive and emotional resources are put into brand building, eventually forming a close brand-consumer relationship. Therefore, like other scholars in related research (Schultz, 2017; Menon et al., 2019), the number of shares, comments and likes of each brand post is used to measure consumer engagement.

\section{Post Content}

Entertaining and informative content are important motivations for consumers to engage in brand-related content (Lee et al., 2018), but research on the relationship between the two content types and consumer engagement has produced inconsistent results. Some studies have confirmed that entertainment has a stronger impact on comments and likes (Park et al., 2009; Rietveld et al., 2020). Some scholars also point out that rational information appeal is more effective than emotional entertainment appeal on consumer engagement (Shahbaznezhad et al., 2020). Entertainment posts are usually humorous videos, anecdotes, jokes, slogans or word games, which do not involve brands or specific products and help consumers enjoy aesthetics and release emotions (Bronstein, 2013). If consumers feel more fun from brand posts, they will have more motivation to visit repeatedly (Ashley et al., 2015). Informative posts are defined as posts about specific enterprises, brands, products or services, including some important announcements (Menon et al., 2019). They can stimulate consumer viewing and interaction and meet the motivation needs of consumers seeking information to make better decisions (Muntinga et al., 2011). In addition, promotional posts are described as a competition, coupon or any form of preferential treatment, which also affects the engagement of brand posts (Hong et al., 2011). Many enterprises carry out promotional activities through social media to attract consumers, but such activities fail to make full use of the interactive functions provided by the platform, resulting in a decrease in consumer engagement (Lee et al., 2018). It may even have a negative impact on brand engagement due to violating consumers' expectations when visiting brand post pages. Therefore, this paper proposes the following hypotheses:

Hla: Posts that contain entertaining content have the greatest impact on consumer engagement.

H1b: Posts that contain information about the brand have a lower impact on consumer engagement compared to entertaining content.

H1c: Posts that offer promotion have a lower impact on consumer engagement than informative content.

\section{Post Form}

The form of the post represents the content that brand managers consider when creating a post in addition to the text, including vividness, interactivity and length.

Vividness refers to the form in which the media environment presents information to the audience's senses, which is related to the depth and breadth of information. Depth represents the quality of information content and the resolution ratio of presentation. Breadth represents the number of sensory dimensions stimulated by content, such as sounds and photos (Steuer, 1992). Studies have confirmed that the vividness of brand posts will affect consumer engagement (Luarn et al., 2015; Schultz, 2017; Menon et al., 2019). However, different media types, such as status, photos, links and videos, have different degrees of appeal to consumers' senses, and may change due to different engagement behaviours such as sharing, commenting and liking. For example, photos and videos have a positive effect on liking (De Vries et al., 2012; Trefzger et al., 2016), and comments are influenced by photos (Sabate et al., 2014). Compared with status or links, photos are more effective in creating good consumer attitudes towards brand posts (Leung et al., 2017). Although the research results are different, they generally support the correlation between the vividness of brand posts and consumer engagement. Therefore, this paper proposes the following assumptions:

H2a. The degree of vividness results in consumer engagement.

Interactivity is defined as the degree to which two or more communicators could interact with each other on communication media and messages, and the degree to which these actions are synchronized (Liu \& Shrum, 2002). Previous studies have explored the influence of different levels of interaction, such as status, links, calls to act, voting and questions, on different levels of consumer engagement, and reached different conclusions. Low interactive posts (status) generate more comments and likes than high interactive posts (links) (Cvijikj \& Michaeles, 2013). Questions represent strong interactivity, leading to more comments (De Vries et al., 2012). Some studies have pointed out that the more interactive brand posts there are, the more likely users are to share, comment and like (Luarn et al., 2015). It is undeniable that interaction brings good communication results. Therefore, this paper proposes the following hypotheses:

$H 2 b$. The degree of interactivity results in consumer engagement.

Length is another index to measure the post form, which refers to the number of characters contained in the brand post. When consumers view brand posts and think about information or issues, their engagement behaviours, including sharing, commenting or liking, depend on the amount of information contained (Zhang $\mathrm{H}$ et al., 2014). The amount of information and the ability of consumers to process information are affected by the length of posts (Trefzger et al., 2016). The research of Antoniadis et al. (2019) confirms this viewpoint, indicating that the length of brand posts has an impact on commenting and sharing. There is also a study that concludes that the length of a post is positively correlated with liking (Sabate et al., 2014). Previous studies on advertising effectiveness also show that message length affects engagement performance indicators such as the click-through rate (Baltas, 2003). Therefore, this paper proposes the following hypotheses:

H2c. The length of a post results in consumer engagement.

\section{Posting Time}

The posting time of brand posts is an important characteristic for the success of posts (Alves et al., 2016). Consumers are more likely to engage in brands at certain times (Jaakonmaki et al., 2017). Golder et al. (2007) find that most consumer interaction activities are carried out 
during workdays, especially from Monday to Wednesday, which are more likely to attract consumer engagement. Dolan et al. (2016) confirm that consumer engagement is higher on Friday than at other times of the week. Villamediana et al. (2019) point out that brand posts published on Thursday and Saturday are helpful to improve active consumer engagement. The research of Lin et al. (2017) further focuses on posting time, indicating that publishing brand posts during peak hours has a significant impact on consumer engagement. It is important for brand managers to ensure that consumers of the brand page are active when posts are published, with the aim of attracting consumers' attention to brand posts. Therefore, this paper proposes the following hypotheses:

H3a: Posts created on workdays have a higher impact on consumer engagement.

H3b: Posts created during peak hours have a higher impact on consumer engagement.

\section{Method}

\section{Data Collection}

The existing literature emphasizes the consumer engagement of different online platforms (Menon et al., 2019), but tends to focus on Facebook (Schultz, 2017). As a representative social media platform in China, Sina Weibo is committed to promoting social empowerment, deepening vertical fields and optimizing user experience (Wang Xiwei et al., 2018). According to the 2018 Weibo user development report released by Sina, as of November 2018, the number of Sina Weibo authentication users with more than 500000 fans increased by $60 \%$ to 47300 . The enthusiasm of Sina Weibo authentication users to generate content continues to rise, with 6.5 million original articles per month, and the social operation effect is good: monthly reads were 1,586 billion, monthly shares were 3.26 million, and monthly active comments were 13.92 million.

Sina Weibo has the typical characteristics of high user activity, strong aggregation and frequent information interaction similar to Facebook, which well represents a social media information platform. Previous studies have confirmed that culture could affect the relationship between brand post characteristics and consumer engagement (Khan et al., 2016). The nations themselves can be used to measure culture because their members share language, institutional system, religion, history and sense of identity (Khan et al., 2016). Although the research on social media consumer engagement provides a reference, the mainstream user groups of Sina Weibo are different from them, which means that cultural differences should be considered when brands manage and make brand posts. Therefore, Sina Weibo is chosen to expand the research on platform diversification.

There are significant differences in the effect of wordof-mouth of different product types (search-based and experience-based) on consumer attitudes (Xuecheng Y et al., 2015). To avoid this difference, this paper selects brands whose products or services are experiential. Specifically, nine well-known brands are determined, including H\&M, ONLY, ZARA, KFC, McDonald's, Dicos, Fliggy, Tuniu and Qunar. The purpose of this is not only to ensure that there is no significant difference in consumers' cognitive level but also to ascertain that consumers have a certain degree of activity to meet the data needs of research.

After determining Sina Weibo and its nine brands, a software agent is selected to collect data. The python code language is used, through setting website cookies in the program, to simulate the user login Sina Weibo. The authentication accounts of nine brands are collected, the corresponding URLs are searched, and then the official brand pages are displayed. The open source Scrapy framework is used to crawl the search results page of Sina Weibo and obtain the target data. The official brand posts and interactive information released from February 12, 2019, to July 12, 2019, are recorded, with a total of 6,409 pieces. The captured information fields include the content of each post, whether there is a link, whether there is a picture or video, the time of publication, number of shares, number of comments, number of likes and other information dimensions (see Figure 2).

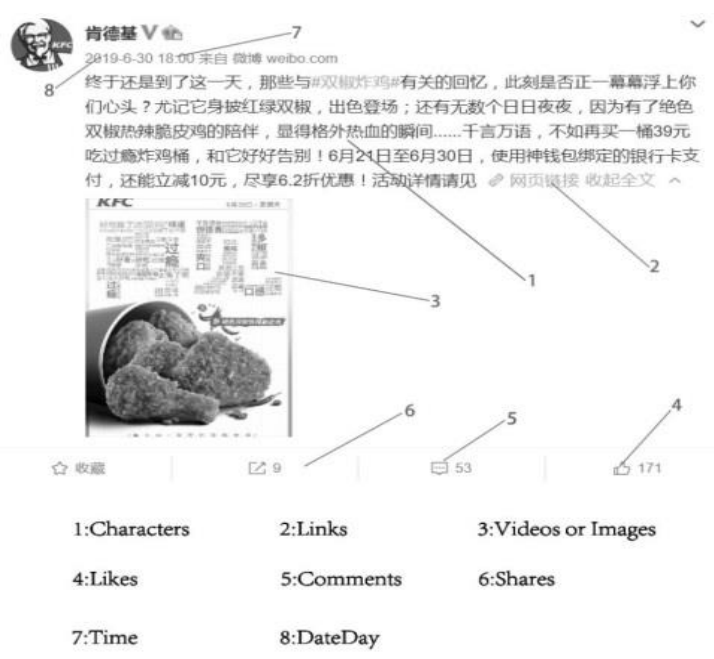

Figure 2. Brand Information Dimension Display Diagram

\section{Operationalization of the Variables}

Share, comment and like. This study explains that the direct manifestation of consumer engagement is the behaviour of interaction with brand posts on social media. Measured by the number of shares, comments and likes on brand posts, they could be collected directly on Sina Weibo.

Post content. To capture the content of brand posts, they are classified into entertaining, informative and promotional content. Manual coding is carried out according to the coding development strategy (Glaser \& Strauss, 1967). Entertainment content refers to the content that makes consumers interested and provides them with pleasure or recreation. They are often expressed in the form of banter, slogans, word games, humour, artistic works, jokes and interesting facts or anecdotes. Information content refers to the information about brands, specific products or services, as well as important announcements and technical details issued to consumers. Promotional content involves various discounts, coupons, trials or other eye-catching preferential activities.

Post form. The publishing form of brand posts mainly considers three elements, including vividness, interactivity and length. 
Existing studies generally divide vividness into four levels, from none to high (De Vries et al., 2012; Cvijikj \& Michahelles, 2013; Luarn et al., 2015). Simple short texts are not vivid. Photo posts, including screenshots, photos or photo collections, reflect low-level vividness. Links provide consumers with additional information, with a medium level of vividness. Videos that provide consumers with more visual and auditory enjoyment represent high vividness.

The operation of interactive characteristics includes four levels: none, low, medium and high, which is consistent with previous studies (Luarn et al., 2015; Schultz, 2017). No interaction means that there is no interactive characteristic in the post, just a simple text. Links that do not directly point to the brand's own website and voting represent low-level interaction. Urging brand fans to do something is classified as moderate interactivity, such as a call to action. Questions including no prizes or prizes reflect a high degree of interactivity. The operational classification of vividness and interactivity is shown in Table 1.

Table 1

Operational Classification of Vividness and Interactivity

\begin{tabular}{|c|c|l|}
\hline Level & Vividness & \multicolumn{1}{c|}{ Interactivity } \\
\hline None & Status & Status \\
\hline Low & Photo & $\begin{array}{l}\text { Link (do not point directly to the } \\
\text { company's own website, mainly to news } \\
\text { sites or blogs) / Voting }\end{array}$ \\
\hline Medium & $\begin{array}{c}\text { Link (all } \\
\text { links) }\end{array}$ & $\begin{array}{l}\text { Call to act (visiting a certain website, } \\
\text { liking, commenting, sharing the post and } \\
\text { entering contests) }\end{array}$ \\
\hline High & Video & $\begin{array}{l}\text { Question (with and without prizes are } \\
\text { included) }\end{array}$ \\
\hline
\end{tabular}

The length of brand posts can be measured by characters (Schultz et al., 2017), words (De Vries et al., 2012) or text lines (Trefzger et al., 2016). This study uses the number of characters.

Posting time. The posting time of brand posts discusses two variants of DOW and peak hour. DOW means that brand posts are published on weekends or workdays. Saturday and Sunday are called weekends. Monday to Friday are collectively referred to as workdays. According to the real situation of the research data obtained, the number of shares, comments and likes are 8,686,389, 1,324,372 and $3,356,442$, respectively, during the period from 10:00 a.m. to 7:00 p.m., which is almost three times as long as the rest of the time. Therefore, the period from 10:00 a.m. to 7:00 p.m. is coded as the peak of consumer activity, and the rest of the time is coded as a low peak.

\section{Descriptive Statistics}

After processing the data according to the variable operation standard, to see how the Sina Weibo brand page uses the selected independent variables and what kind of dependent variable feedback is obtained, this paper first carries out a descriptive statistical analysis of the data.

Brand managers use different post characteristics to stimulate consumer engagement. Table 2 shows that in 55.2 $\%$ of brand posts, brands convey information about brands, products or services to consumers. Entertainment posts accounted for $34 \%$, and the utilization rate was high. Regarding vividness and interactivity, $97 \%$ of brand posts contain vividness and $50 \%$ of brand posts have interactivity. Specifically, the proportion of photos in vividness is at most
$51.1 \%$, and the utilization rate of videos is at least $19.3 \%$. The frequency of calls to act is obviously higher than that of other interactive brand posts. Less than $3 \%$ of the voting for inanimate and low-level interactivity is rarely found in posts. Because these characteristics have not changed much, this paper decided not to consider them in further analysis. The number of posts published by brands on workdays and peak hours is relatively high, which agrees with daily rules. The average length of brand posts is 105 characters.

Table 2

Descriptive Statistics of Variables

\begin{tabular}{|c|c|c|c|c|}
\hline Variables & Level & $\begin{array}{c}\text { Operationali } \\
\text { zation }\end{array}$ & Count & Percent \\
\hline \multirow{3}{*}{ Content } & Low & Promotion & 696 & 10.9 \\
\cline { 2 - 5 } & Medium & Information & 3537 & 55.2 \\
\cline { 2 - 5 } & High & Entertaining & 2176 & 34.0 \\
\hline \multirow{4}{*}{ Vividness } & None & Status & 193 & 3.0 \\
\cline { 2 - 5 } & Low & Photos & 3278 & 51.1 \\
\cline { 2 - 5 } & Medium & Links & 1704 & 26.6 \\
\cline { 2 - 5 } & High & Videos & 1234 & 19.3 \\
\hline \multirow{4}{*}{ Interactivity } & None & Status & 3202 & 50.0 \\
\cline { 2 - 5 } & Low & Links & 1037 & 16.2 \\
\cline { 2 - 5 } & Medium & Voting & 3 & 0.0 \\
\cline { 2 - 5 } & High & Questions & 1529 & 23.9 \\
\hline \multirow{2}{*}{ DOW } & Low & Weekend & 1212 & 10.0 \\
\cline { 2 - 5 } & High & Workday & 5197 & 81.1 \\
\hline \multirow{2}{*}{ Peak Hour } & Low & Low Hour & 2425 & 37.8 \\
\cline { 2 - 5 } & High & Peak Hour & 3984 & 62.2 \\
\hline Variables & \multicolumn{2}{|c|}{ Operationalization } & M & SD \\
\hline Length & Number of characters & 105.09 & 60.85 \\
\hline Like & \multicolumn{2}{|c|}{ Number of likes } & 718.90 & 3163.68 \\
\hline Comment & \multicolumn{2}{|c|}{ Number of comments } & 282.27 & 1344.67 \\
\hline Share & \multicolumn{2}{|c|}{ Number of shares } & 1824.13 & 20894.16 \\
\hline
\end{tabular}

\section{Construction of Evaluation Index System of Consumer Engagement}

According to the proposed conceptual framework and descriptive analysis results, the characteristic and characteristic values of consumer engagement are attributed to different levels, forming a multilevel evaluation index system structure. The content, vividness, interactivity, DOW and peak hour are the first-level characteristics, and the characteristic values contained in them are the second-level characteristics. As a decision characteristic, consumer engagement is measured by sharing, liking and commenting. Based on this, the evaluation index system of consumer engagement is completed. The details are shown in Figure 3.

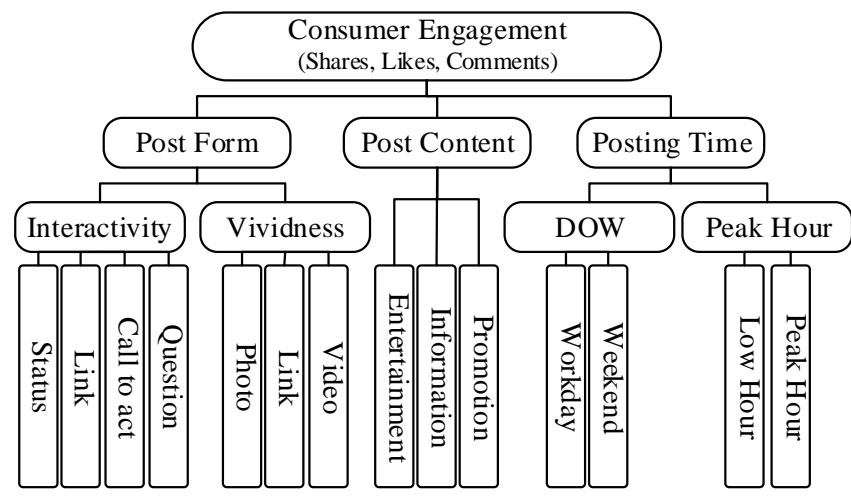

Figure 3. Evaluation index system of consumer engagement 


\section{Data Preprocessing}

As a mathematical tool for dealing with ambiguity and uncertainty, RS can deal effectively with discrete data, but it cannot be applied to continuous data. The normalized index data is still continuous. Therefore, before characteristic reduction and rule extraction, appropriate methods should be used to discretize the characteristic set to meet the data requirements.

Table 2 shows that the variances of continuous variables post length, number of likes, number of comments and number of shares are $60.85,3,163.68,1,344.67$ and 20,894.16, respectively, which shows that there is a large difference between most values and average values of variables, and the degree of dispersion is large. To eliminate the influence of data dispersion as much as possible, the tail shrinking treatment is adopted to eliminate $1 \%$ of the abnormal data before and after, and the natural logarithm of all continuous variables is taken to ensure good discretization results. In addition, data where consumer engagement equals zero are eliminated (Bekiros et al., 2018).

There are many methods of data discretization. The Kmeans clustering algorithm used in this paper is a widely used algorithm (Liangjun et al., 2015). MATLAB 2014b is used to write codes to discretize of continuous variables such as length, number of likes, number of comments and number of shares. Combined with the characteristics of the data, many experiments were carried out by comparing the results, of which the $\mathrm{K}$ value was determined to be 3 . Among them, L3, L2 and L1 represent long, medium and short levels of post length, respectively, which is subordinate to conditional characteristics. The behaviours of sharing, commenting and liking in consumer engagement are decision characteristics, which are represented by R, M and $\mathrm{K}$, respectively. Each decision characteristic is divided into three grades, including high, medium and low.

In addition, for the classified variables in the dataset, the different categories of each variable are equivalent to the discretization results. For example, vividness is a threecategory variable, including three values of photos, links and videos. If represented by $\mathrm{V}$, the discretization result is $V=\left\{V_{1}=\right.$ photo $; V_{2}=$ link $; V_{3}=$ video $\}$. To make the later analysis clear, the category and identification of dependent and independent variables of consumer engagement are described, as shown in Table 3.

\section{Data Analysis}

After the data are ready, $\mathrm{RS}$ analysis is performed according to the constructed decision table of consumer engagement (see Figure 3). The rough set tool Rosetta is used to reduce characteristics and generate rules to study the relationship between the post content, form and posting time and consumer engagement. The Rosetta system was established by Ohrn (1999) on the basis of rough set methodology. It supports a continuous process from the initial stage of data preprocessing to calculating the minimum set of characteristics, refining if-then rules, and finally acquiring knowledge.

After importing the data into Rosetta, the algorithm of Holte $1 \mathrm{R}$ is selected for reduction. The reason is that the algorithm provides the optimal results by automatically generating rules and returns all singleton characteristic sets and corresponding $1 \mathrm{R}$ rule sets, namely, univariate decision rules, to complete the analysis of association rules between characteristics and consumer engagement. The theoretical basis of the reduction algorithm refers to the literature (Holte, 1993).

Table 3

Description of Consumer Engagement Characteristics

\begin{tabular}{|c|c|c|c|c|}
\hline \multicolumn{2}{|c|}{ Characteristic } & Category & Identification & Count \\
\hline \multirow{3}{*}{\multicolumn{2}{|c|}{ Post Content }} & Entertainment & C3 & 1754 \\
\hline & & Information & $\mathrm{C} 2$ & 2818 \\
\hline & & Promotion & $\mathrm{C} 1$ & 584 \\
\hline \multirow{10}{*}{ Post Form } & \multirow{3}{*}{ Vividness } & Photo & V1 & 2877 \\
\hline & & Link & $\mathrm{V} 2$ & 1202 \\
\hline & & Video & V3 & 1077 \\
\hline & \multirow{4}{*}{ Interactivity } & Status & I1 & 2731 \\
\hline & & Link & $\mathrm{I} 2$ & 659 \\
\hline & & Call to act & I3 & 1269 \\
\hline & & Question & $\mathrm{I} 4$ & 497 \\
\hline & \multirow{3}{*}{ Length $^{*}$} & $16-50$ & L1 & 985 \\
\hline & & $51-108$ & L2 & 1746 \\
\hline & & $109-260$ & L3 & 2425 \\
\hline \multirow{4}{*}{$\begin{array}{l}\text { Posting } \\
\text { Time }\end{array}$} & \multirow{2}{*}{ DOW } & Workday & W1 & 4160 \\
\hline & & Weekend & W2 & 996 \\
\hline & \multirow{2}{*}{ Peak Hour } & Peak Hour & H1 & 3182 \\
\hline & & Low Hour & $\mathrm{H} 2$ & 1974 \\
\hline \multirow{9}{*}{$\begin{array}{c}\text { Consumer } \\
\text { Engagement }\end{array}$} & \multirow{3}{*}{$\begin{array}{c}\text { Number of } \\
\text { like }^{*}\end{array}$} & $1-40$ & K1 & 2301 \\
\hline & & $41-550$ & $\mathrm{~K} 2$ & 2329 \\
\hline & & $557-16070$ & K3 & 526 \\
\hline & \multirow{3}{*}{$\begin{array}{l}\text { Number of } \\
\text { comment }^{*}\end{array}$} & $1-14$ & M1 & 2187 \\
\hline & & $15-177$ & M2 & 2251 \\
\hline & & $178-5838$ & M3 & 718 \\
\hline & \multirow{3}{*}{$\begin{array}{c}\text { Number of } \\
\text { share }^{*}\end{array}$} & $1-5$ & R1 & 1679 \\
\hline & & $6-205$ & $\mathrm{R} 2$ & 2776 \\
\hline & & $206-37522$ & R3 & 701 \\
\hline
\end{tabular}

* is the discretization result of continuous data. In order to reduce the impact of data decentralization, the natural logarithm is taken first and then discretized. Therefore, the numerical span before logarithm may be large, which is normal.

\section{Results}

With the Rosetta tool, the algorithm of Holte $1 \mathrm{R}$ is used to reduce characteristics and automatically generate rules. Set the minimum support to $5 \%$ and the minimum confidence to $50 \%$. The final association rule results are separately shown in Table 4, Table 5 and Table 6.

\section{Association Rule Model of Share}

Post Content. In terms of post content, the support for entertainment, information, and promotional content are $37.79 \%, 52.31 \%$, and $9.91 \%$ respectively, representing that the decision rules generated by the three characteristics are representative. The confidence of entertainment and information content are $59.81 \%$ and $51.53 \%$, respectively, which indicates that the credibility of entertainment content in stimulating consumers to share is $59.81 \%$, and the credibility of information content triggering sharing is $51.53 \%$. Both reach R2 $(6<\mathrm{R} 2<205)$. In contrast, interesting and humorous content is more likely to encourage consumers to share brand-related content online, followed by information content. The confidence of promotional content is $47.09 \%$, which is not significant. Hypotheses $\mathrm{H} 1 \mathrm{a}, \mathrm{H} 1 \mathrm{~b}$, and H1c are confirmed.

Post Form. Regarding vividness, the support of photos, links, and videos is $63.22 \%, 46.70 \%$, and $27.16 \%$, respectively, implying that the decision-making rules based on 
the three are significant to analyse. Table 5 shows that the confidence of photos, links and videos are $61.00 \%, 65.22 \%$ and $70.01 \%$, respectively, which are all important characteristics affecting sharing. This supports H2a. Among them, photos or videos further enhance the influence and communication power of posts, and drive consumers to produce a higher level of sharing behaviour R2 $(6<\mathrm{R} 2<205)$. Videos activate consumers' vision and hearing at the same time, making the credibility of decisions affecting the number of shares 10 percentage points higher than that of photos, which highlights the advantages of video in sharing. Links also play a role in the behaviour of sharing, but they are more likely to stimulate low-level sharing behaviour R1 $(1<\mathrm{R} 1<5)$.

Association Rule Results of Share

Table 4

\begin{tabular}{|c|c|c|c|c|c|c|}
\hline Num & & Primary characteristic & Association rule & Secondary characteristic & Confidence & Support \\
\hline 1 & \multirow{3}{*}{ Post Content } & \multirow{3}{*}{ Content } & $\mathrm{C} 3=>\mathrm{R} 2$ & Entertainment & 0.5981 & 0.3779 \\
\hline 2 & & & $\mathrm{C} 2 \Rightarrow \mathrm{R} 2$ & Information & 0.5153 & 0.5231 \\
\hline 3 & & & $\mathrm{C} 1=>\mathrm{R} 2$ & Promotion & 0.4709 & 0.0991 \\
\hline 4 & \multirow{10}{*}{ Post Form } & \multirow{3}{*}{ Vividness } & $\mathrm{V} 1=>\mathrm{R} 2$ & Photo & 0.6100 & 0.6322 \\
\hline 5 & & & $\mathrm{~V} 2=>\mathrm{R} 1$ & Link & 0.6522 & 0.4669 \\
\hline 6 & & & $\mathrm{~V} 3=>\mathrm{R} 2$ & Video & 0.7001 & 0.2716 \\
\hline 8 & & \multirow{4}{*}{ Interactivity } & $\mathrm{I} 1=>\mathrm{R} 2$ & Status & 0.6613 & 0.6506 \\
\hline 9 & & & $\mathrm{I} 2=>\mathrm{R} 1$ & Link & 0.7891 & 0.3097 \\
\hline 10 & & & $\mathrm{I} 3=>\mathrm{R} 2$ & Call to act & 0.4799 & 0.2194 \\
\hline 11 & & & $\mathrm{I} 4=>\mathrm{R} 2$ & Question & 0.5211 & 0.0933 \\
\hline 12 & & \multirow{3}{*}{ Length } & $\mathrm{L} 1=>\mathrm{R} 2$ & $16-50$ & 0.6660 & 0.2363 \\
\hline 13 & & & $\mathrm{~L} 2 \Rightarrow \mathrm{R} 2$ & $51-108$ & 0.4507 & 0.2835 \\
\hline 14 & & & $\mathrm{~L} 3=>\mathrm{R} 2$ & $109-260$ & 0.5497 & 0.4802 \\
\hline 15 & \multirow{4}{*}{ Posting Time } & \multirow{2}{*}{ DOW } & $\mathrm{W} 1=>\mathrm{R} 2$ & Workday & 0.5344 & 0.8008 \\
\hline 16 & & & $\mathrm{~W} 2=>\mathrm{R} 2$ & Weekend & 0.5552 & 0.1992 \\
\hline 17 & & \multirow{2}{*}{ Peak Hour } & $\mathrm{H} 2 \Rightarrow \mathrm{R} 2$ & Low Hour & 0.5567 & 0.3959 \\
\hline 18 & & & $\mathrm{H} 1=>\mathrm{R} 2$ & Peak Hour & 0.5270 & 0.6041 \\
\hline
\end{tabular}

In terms of interactivity, the support of status, links and call to act are all higher than the basic requirements of $5 \%$, which are $65.06 \%, 30.97 \%$ and $21.94 \%$ respectively. Although the support of questions is lower than other characteristics, it is $4 \%$ higher than the benchmark. The corresponding decision rules formed by all characteristics under the interaction have an exemplary role. The confidence of status and questions are $66.13 \%$ and $52.11 \%$, respectively, both of which effectively influence consumers and trigger sharing behaviour at the R2 level $(6<\mathrm{R} 2<205)$. Links have $78.91 \%$ probability of stimulating low-level sharing behaviour R1 $(1<\mathrm{R} 1<5)$. The confidence of calls to act is $47.99 \%$, which has no significant impact on sharing. This partly supports $\mathrm{H} 2 \mathrm{~b}$.

As far as the length of posts is concerned, the support of the association rules between length in the range of L1, L2 and L3 and sharing are all above $20 \%$, and the confidence of which is $66.60 \%, 45.07 \%$ and $54.97 \%$, respectively. L1 and L3 induce consumers to share at the same level $(6<\mathrm{R} 2<205)$, but L1 induces R2 with higher credibility. When the number of characters in the post is within the L2 range, the credibility of inspiring consumers to share is not significant. This proves that different lengths have different effects on sharing. Partly supports Hypothesis H2c.

Posting Time. For posting time, the support for publishing posts on workdays is $80.08 \%$, and that on weekends is $19.92 \%$. The ratio of support shows the remarkable representativeness of the data. Posts published on workdays or weekends motivate the same sharing level $\mathrm{R} 2(6<\mathrm{R} 2<205)$, and their credibility is $53.44 \%$ and 55.52 $\%$, respectively. By comparison, brand posts created on weekend have a greater impact on sharing. H3a is not supported.

The support for the corresponding decision rules generated by posts published during peak hours and low hours are $60.41 \%$ and $39.59 \%$, respectively, indicating that these two association rules are obviously representative and analysable. According to the confidence, the credibility of the decision rules that stimulate the behaviour of sharing at the R2 level $(6<\mathrm{R} 2<205)$ in the peak hour is $52.70 \%$. The difference between low and peak hours is small, but the reliability of the generated association rules about sharing behaviour R2 $(6<\mathrm{R} 2<205)$ is approximately $3 \%$ higher. $\mathrm{H} 3 \mathrm{~b}$ is not supported. Although the posts published during peak hours and low hours all influence sharing, the difference is not obvious.

\section{Association Rule Model of Comment}

Post Content. For post content, the support of entertainment, informational and promotional content meets the basic support requirements, and the corresponding association rules generated have a certain representative significance. The confidence of promotional content is 49.66 $\%$, which indicates that it promotes the low credibility of consumer comment behaviour M2 $(15<\mathrm{M} 2<177)$, and has no significant effect on commenting. Information and entertainment content significantly influence the number of comments, with confidence levels of $51.60 \%$ and $51.43 \%$, respectively, which shows that both have a positive effect on encouraging consumers to comment. Among them, informational content induces consumers to direct more attention to the information itself, resulting in low-level 
consumer comment behaviour M1 $(1<\mathrm{M} 1<14)$. When the brand uses a humorous way to convey information, it is easier to increase consumers' enthusiasm for commenting at the M2 level $(15<M 2<177)$. In summary, the characteristics that affect comments are entertainment, information, and promotion. H1a, H1b, and H1c are confirmed.

Table 5

Association Rule Results of Comment

\begin{tabular}{|c|c|c|c|c|c|c|}
\hline Num & & Primary characteristic & Association rule & Secondary characteristic & Confidence & Support \\
\hline 1 & \multirow{3}{*}{ Post Content } & \multirow{3}{*}{ Content } & $\mathrm{C} 3=>\mathrm{M} 2$ & Entertainment & 0.5143 & 0.4007 \\
\hline 2 & & & $\mathrm{C} 2=>\mathrm{M} 1$ & Information & 0.5160 & 0.6648 \\
\hline 3 & & & $\mathrm{C} 1=>\mathrm{M} 2$ & Promotion & 0.4966 & 0.1288 \\
\hline 4 & \multirow{10}{*}{ Post Form } & \multirow{3}{*}{ Vividness } & $\mathrm{V} 1=>\mathrm{M} 2$ & Photo & 0.4651 & 0.5944 \\
\hline 5 & & & $\mathrm{~V} 2=>\mathrm{M} 1$ & Link & 0.6082 & 0.3342 \\
\hline 6 & & & $\mathrm{~V} 3=>\mathrm{M} 2$ & Video & 0.5422 & 0.2594 \\
\hline 8 & & \multirow{4}{*}{ Interactivity } & $\mathrm{I} 1=>\mathrm{M} 2$ & Status & 0.4548 & 0.5518 \\
\hline 9 & & & $\mathrm{I} 2=>\mathrm{M} 1$ & Link & 0.7891 & 0.2378 \\
\hline 10 & & & $\mathrm{I} 3=>\mathrm{M} 2$ & Call to act & 0.4752 & 0.2679 \\
\hline 11 & & & $\mathrm{I} 4=>\mathrm{M} 2$ & Question & 0.6117 & 0.1351 \\
\hline 12 & & \multirow{3}{*}{ Length } & L1 => M1 & $16-50$ & 0.5096 & 0.2295 \\
\hline 13 & & & $\mathrm{~L} 2=>\mathrm{M} 1$ & $51-108$ & 0.5000 & 0.3992 \\
\hline 14 & & & $\mathrm{~L} 3=>\mathrm{M} 2$ & $109-260$ & 0.4660 & 0.5020 \\
\hline 15 & \multirow{4}{*}{ Posting Time } & \multirow{2}{*}{ DOW } & $\mathrm{W} 1=>\mathrm{M} 2$ & Workday & 0.4358 & 0.8054 \\
\hline 16 & & & $\mathrm{~W} 2 \Rightarrow \mathrm{M} 2$ & Weekend & 0.4398 & 0.1946 \\
\hline 17 & & \multirow{2}{*}{ Peak Hour } & $\mathrm{H} 2=>\mathrm{M} 2$ & Low Hour & 0.4473 & 0.3923 \\
\hline 18 & & & $\mathrm{H} 1 \Rightarrow \mathrm{M} 2$ & Peak Hour & 0.4299 & 0.6077 \\
\hline
\end{tabular}

Post Form. With regard to vividness, the support of photos, links or videos is above $25 \%$, which indicates that they account for a large proportion of the total sample, and the corresponding generated rules are remarkably representative. Consumers' comment behaviour is mainly affected by links and videos. The confidence level of links is $60.82 \%$, and the generated association rules are at the M1 $(1<\mathrm{M} 1<14)$ baseline. The credibility of video stimulating high-level commenting M2 $(15<\mathrm{M} 2<177)$ is $54.22 \%$. Comparing links and videos shows that links have the possibility of distracting consumer attention, resulting in fewer comments posted by consumers. Videos that give consumers visual and auditory enjoyment have richer vivid characteristics and encourage consumers to make more comments. Although the picture has the highest support, its confidence is less than $50 \%$, which is difficult to influence commenting. $\mathrm{H} 2 \mathrm{a}$ is partially verified.

In terms of interactivity, the support for status and call to act is $55.18 \%$ and $26.79 \%$, respectively, indicating that the corresponding rules generated are representative. However, the confidence of both is less than $50 \%$, which has no significant impact on the number of comments. The rules generated by links with support of $23.78 \%$ and questions with support of $13.51 \%$ are also analysable. In particular, the confidence of links and questions is $78.91 \%$ and $61.17 \%$ respectively, which could trigger consumers' cognition and emotional expression for posts. The difference is that links tend to motivate consumers to comment at the level of $\mathrm{M} 1 \quad(1<\mathrm{M} 1<14)$, while questions induce more comments of M2 $(15<\mathrm{M} 2<177)$. H2b is partially supported.

Regarding post length, the confidence of posts with L1 characters is $50.97 \%$ and that of posts with lengths within L2 is $50.00 \%$. In addition, the credibility of the corresponding association rules is basically the same, both of which promote consumers to generate an M1 $(1<\mathrm{M} 1<14)$ level of commenting. The confidence of the longest post of L3 is only $46.60 \%$, which has no significant impact on the number of comments. Generally, the relationship between brand post length and commenting behaviour is not significant. $\mathrm{H} 2 \mathrm{c}$ is partially confirmed.

Posting Time. In terms of posting time, the support of posts published on workdays and weekends are $80.54 \%$ and $19.46 \%$, and their confidence levels are $43.58 \%$ and $43.98 \%$ respectively, which clearly state that regardless of whether on weekdays or weekends, posts released have no significant impact on commenting. H3a does not hold.

The support of posts published in peak hours is $60.77 \%$, which indicates that brands issue many posts in peak hours when the number of interactions between consumers and brands is within the range of M2 $(15<\mathrm{M} 2<177)$. The credibility of posts published in peak hours to prompt consumers to comment is $44.06 \%$, while that in low hours to induce consumers to express their feelings or experiences is $46.81 \%$. Neither of them plays an important role in commenting. H3b is not valid.

\section{Association Rule Model of Like}

Post Content. The support of entertainment content and promotional content are $40.58 \%$ and $13.57 \%$ respectively, displaying that the corresponding association rules are representative. The credibility of liking triggered by entertainment content is $53.88 \%$, and that caused by promotional content is $54.11 \%$. Both of them are the key characteristics affecting the number of likes and give impetus to liking with $\mathrm{K} 2$ level $(41<\mathrm{K} 2<550)$. The difference between them is not apparent, and H1a is not confirmed. The release of brand-related information will also make consumers feel like it, and then praise it, but the degree of like is low, only kept at the level of $\mathrm{K} 1$ $(1<\mathrm{K} 1<40)$. In contrast, the effect of informational content on liking is lower than that of entertainment and promotional content. H1b is supported, and H1c fails to be confirmed. 
Association Rule Results of Like

\begin{tabular}{|c|c|c|c|c|c|c|}
\hline Num & & Primary characteristic & Association rule & Secondary characteristic & Confidence & Support \\
\hline 1 & \multirow{3}{*}{ Post Content } & \multirow{3}{*}{ Content } & $\mathrm{C} 3=>\mathrm{K} 2$ & Entertainment & 0.5388 & 0.4058 \\
\hline 2 & & & $\mathrm{C} 2=>\mathrm{K} 1$ & Information & 0.5302 & 0.4586 \\
\hline 3 & & & $\mathrm{C} 1 \Rightarrow \mathrm{K} 2$ & Promotion & 0.5411 & 0.1357 \\
\hline 4 & \multirow{10}{*}{ Post Form } & \multirow{3}{*}{ Vividness } & $\mathrm{V} 1=>\mathrm{K} 2$ & Photo & 0.4977 & 0.6145 \\
\hline 5 & & & $\mathrm{~V} 2 \Rightarrow \mathrm{K} 1$ & Link & 0.6381 & 0.3333 \\
\hline 6 & & & $\mathrm{~V} 3=>\mathrm{K} 2$ & Video & 0.5302 & 0.2452 \\
\hline 8 & & \multirow{4}{*}{ Interactivity } & $\mathrm{I} 1=>\mathrm{K} 2$ & Status & 0.4771 & 0.5595 \\
\hline 9 & & & $\mathrm{I} 2=>\mathrm{K} 1$ & Link & 0.7451 & 0.2134 \\
\hline 10 & & & $\mathrm{I} 3=>\mathrm{K} 2$ & Call to act & 0.5051 & 0.2752 \\
\hline 11 & & & $\mathrm{I} 4=>\mathrm{K} 2$ & Question & 0.5191 & 0.1108 \\
\hline 12 & & \multirow{3}{*}{ Length } & $\mathrm{L} 1 \Rightarrow \mathrm{K} 1$ & $16-50$ & 0.5381 & 0.2303 \\
\hline 13 & & & $\mathrm{~L} 2=>\mathrm{K} 1$ & $51-108$ & 0.5120 & 0.3885 \\
\hline 14 & & & $\mathrm{~L} 3=>\mathrm{K} 2$ & $109-260$ & 0.4755 & 0.4951 \\
\hline 15 & \multirow{4}{*}{ Posting Time } & \multirow{2}{*}{ DOW } & $\mathrm{W} 1=>\mathrm{K} 1$ & Workday & 0.4611 & 0.8336 \\
\hline 16 & & & $\mathrm{~W} 2 \Rightarrow \mathrm{K} 1$ & Weekend & 0.5070 & 0.2168 \\
\hline 17 & & \multirow{2}{*}{ Peak Hour } & $\mathrm{H} 2 \Rightarrow \mathrm{K} 1$ & Low Hour & 0.4539 & 0.3894 \\
\hline 18 & & & $\mathrm{H} 1 \Rightarrow \mathrm{K} 2$ & Peak Hour & 0.4516 & 0.6170 \\
\hline
\end{tabular}

Post Form. For vividness, $61.49 \%$ of the photos are liked by consumers $(41<\mathrm{K} 2<550)$, but the confidence is only $49.77 \%$, which shows that although the usage rate of photos in brand posts is high, the effect of photos on liking is not up to expectations. The confidence of association between links and liking is $63.81 \%$, and the support is $33.33 \%$, while the confidence and support of the association between video and liking are $53.02 \%$ and $24.52 \%$ respectively. This demonstrates that both links and videos could effectively stimulate consumer feelings of liking. Hypothesis $\mathrm{H} 2 \mathrm{a}$ is partially supported. However, links drive low-level liking, while videos enhance the liveliness of brand posts and promote consumers to have a deeper level of liking. Photos and videos are equally liked by consumers $(41<\mathrm{K} 2<550)$. In comparison, the confidence of photos is lower than that of videos, intimating that when a brand post contains videos, it is more likely to make consumers like it. Generally, videos are more attractive and persuasive than photos.

For interactivity, the support of links is $21.34 \%$, which demonstrates that links account for a high proportion of the consumer preference characteristics that stimulate $\mathrm{K} 1$ $(1<\mathrm{K} 1<40)$. When like to be at the level of $\mathrm{K} 2$ $(41<\mathrm{K} 2<550)$, the proportion of status corresponding rules is up to $55.95 \%$, which is more symbolic. The support of calls to act is $27.52 \%$, and the support of questions is $11.08 \%$, which shows that the decision rules generated by both are representative to some extent. The confidence of the links, call to act and questions is $74.51 \%, 50.51 \%$ and $51.91 \%$, respectively, which proves that the association rules generated by the three characteristics are credible, and all of them have strong explanatory power on liking. Consumers' liking for links remains at $\mathrm{K} 1(1<\mathrm{K} 1<40)$, while their liking for calling to act and questions is maintained at $\mathrm{K} 2$ $(41<\mathrm{K} 2<550)$. Compared with links, posts containing calls to act and questions more easily obtain consumers' love. The confidence level of association rules between status and liking is $47.71 \%$, which indicates that the relationship between them is not close. $\mathrm{H} 2 \mathrm{~b}$ is partially confirmed.
Regarding post length, posts with lengths of L1 or L2 cause the same number of likes $(1<\mathrm{K} 1<40)$, which supports the corresponding decision rules with $53.81 \%$ and $51.20 \%$ confidence respectively. L3 has a credibility of $47.55 \%$ and has no significant effect on liking. Hypothesis $\mathrm{H} 2 \mathrm{c}$ is partially authenticated.

Posting Time. As far as posting time is concerned, the post created on the weekend promotes consumers to produce the behaviour of liking, kept at the level of $\mathrm{K} 1 \quad(1<\mathrm{K} 1<40)$, with a support of $21.68 \%$ and a confidence of $50.70 \%$, which shows that the decision rule is representative and authentic. Although the association rules formed by posts posted on workdays have a high support of $83.36 \%$, the confidence is low at $46.11 \%$, which does not significantly affect the number of likes. In comparison, posts published on weekends bring better interactive experiences to consumers. H3a is not supported.

Brand posts published in peak hours or low hours arouse different levels of liking with $\mathrm{K} 2(41<\mathrm{K} 2<550)$ or $\mathrm{K} 1$ $(1<\mathrm{K} 1<40)$. However, regardless of peak or low hours, the credibility of the association rules to induce liking behaviour is approximately $45 \%$, which makes it difficult to ensure an effective effect. $\mathrm{H} 3 \mathrm{~b}$ is not valid. In summary, the test results of the research hypothesis are shown in Table 7.

\section{Discussion and Managerial Implications}

\section{Post Content}

It is found that content type is one of the important components of the post-publishing strategy, which greatly improves consumer engagement (Menon et al., 2019).

Entertainment and informative content affect sharing, commenting and liking, and the former is proven to be more influential. This may be because when brand managers use humour and wit or emotional language and inspiring stories to convey information, trigger stronger emotional reactions of consumers. Thus, brands establish contact with consumers at the emotional level (Ding \& Tseng, 2015). Compared with informative content, posts containing 
entertainment enhance consumer engagement, which is consistent with the results of Cvijikj \& Michahelles (2013).

Table 7

Test Results of Research Hypothesis

\begin{tabular}{|c|c|c|c|}
\hline Num & Shares & Comments & Likes \\
\hline H1a & Support & Support & Not Support \\
\hline H1b & Support & Support & Support \\
\hline H1c & Support & Support & Not support \\
\hline H2a & Support & Partial Support & Partial Support \\
\hline H2b & Partial support & Partial Support & Partial Support \\
\hline H2c & Partial Support & Partial Support & Partial Support \\
\hline H3a & Not Support & No Effect & Not Support \\
\hline H3b & Not Support & No Effect & No Effect \\
\hline
\end{tabular}

Sharing, commenting and liking are also influenced by informative content. One explanation is that informative posts highlight detailed information about brands, products or services. Consumers' motivation to obtain information, reduce the uncertainty of consumer purchases, and help consumers make wise purchase decisions could be satisfied by browsing them. In addition, providing consumers with information posts about new products and other aspects could satisfy consumers' curiosity (Tafesse, 2015).

This study confirms the view of Luarn et al. (2015) that promotional content increases consumer engagement mainly through liking, but there is no significant effect on sharing and commenting. One possible reason is that consumers who engage in social media tend to acquire and exchange relevant information and experience or entertain with brands or other consumers. However, promotional posts are only regarded as a means of brand sales or publicity, which weakens the ability of posts to create more consumer engagement (Leeflang et al., 2014).

In summary, the above discussion has the following management implications:

Mla: Brand page managers of Sina Weibo should create entertaining posts to provide entertainment for consumers to improve the overall level of consumer engagement.

M1b: Brand page managers of Sina Weibo should post informative posts to provide consumers with information about enterprises, brands, products or services to enhance consumer engagement at different levels.

M1c: Brand page managers of Sina Weibo should post promotional posts to increase the number of likes.

\section{Post Form}

Vividness. Previous studies have shown that vividness affects consumers' online engagement (Schultz, 2017).

It is worth noting that photos representing low vividness are conducive to increasing consumers' desire to share, but have no effect on commenting or liking. This is because photos often induce consumers' emotional reactions rather than cognitive reactions such as commenting. Therefore, sharing, as an emotional expression that hopes more consumers will see a certain post, is more likely to be triggered. Meanwhile, the media content and consumer expectations are constantly evolving, and photos tend to be common in posts, which results in consumers' low expectations and surprises for minimum vividness (Schultz, 2017), and cannot effectively stimulate liking.

The video enriches the vividness and creation of post content, and measures consumer engagement by sharing, commenting and liking. At the same level, the credibility of the rules that video stimulates consumers to share is $70.01 \%$, the credibility of the rules that trigger commenting is $54.22 \%$, and the lowest credibility of the rules that induce consumers to like is $53.02 \%$. The above data highlight that although videos are time-consuming for consumers, consumers are more willing to share videos with their friends, which confirms the research results of Menon et al. (2019) and Antoniadis et al. (2019).

Although links affect consumer engagement, compared with photos and videos, they only affect the lowest level of sharing, commenting and liking. One explanation is that posts containing links provide additional information for consumers. The existence of these external resources may distract consumers' attention, prevent consumers from engaging in the post itself, and increase the risk that consumers will no longer pay attention to the post. This is consistent with the research results of Liu et al. (2012).

The following are the management implications from the above discussion:

Summarize the above discussion in the form of management meaning:

M2al: Brand page managers of Sina Weibo should pay attention to the vividness of posts, such as photos, links or videos, and increase the audience and influence of posts by promoting consumer sharing.

M2a2: Brand page managers of Sina Weibo should pay attention to the role of videos in sharing, commenting and liking but also pay attention to controlling the duration of videos.

M2a3: Brand page managers of Sina Weibo should consider that links will reduce the number of shares, comments and likes and use this element appropriately.

Interactivity. Consistent with previous research (Luarn et al., 2015; Schultz, 2017), different interaction characteristics have a significant impact on the level of social media engagement by liking, commenting and sharing.

In this study, status has no significant influence on comments and likes. However, interestingly, there is a strong correlation between status and sharing. One explainable reason is that status contains a large proportion of entertainment content (1072 posts, accounting for nearly $40 \%$ of status), and entertainment content has a significant impact on sharing. In addition, it takes less time and cost to forward status, which reduces the threshold of sharing by consumers to a certain extent.

The results of this study indicate that low interaction (links) is bound up with three kinds of consumer engagement, but the level of stimulating consumer engagement is the lowest. The interactive nature of links directly leads consumers to other websites, resulting in less commenting or sharing. The external content pointed to could not attract consumers who are more interested in the brand itself or the information related to it, so it could not be liked by consumers (Menon et al., 2019). 
Similar to the research of Menon et al. (2019), calls to act have no significant impact on sharing and commenting and fail to achieve the expected results. However, brand posts containing induced behaviours encourage consumers to seek direct contact with brands, so that they can experience the feeling of being cared for and valued, and effectively enhance consumers' liking.

At the same level of engagement, questions have the greatest impact on consumer engagement. The influence on liking is reflected in the fact that consumers see an interesting question and feel happy. The impact on sharing is that consumers may be willing to share a question with friends to obtain interesting answers (Cvijikj \& Michahells, 2013; Luarn et al., 2015). The effect of questioning on comments is an intuitive result, because consumers could only answer questions through comments.

The management implications of the above discussion are summarized as follows:

M2b1: Brand page managers of Sina Weibo should emphasize the use of questions to improve the overall level of consumer engagement.

M2b2: Even if brand page managers of Sina Weibo use links, they should prioritize the brand's own content to the best of its ability instead of directing consumers to other websites or external content unrelated to the brand itself.

Length. Among all association rules of post length with confidence greater than $50 \%$, only sharing showed a medium level, which indicates that the length of a post, as an operational form of information, has a stronger impact on the number of shares. However, if brand page managers expect posts to be more likely to be shared, they should ensure posts short. The number of characters is best in the range of 16-50. The research results of Zhang L et al. (2014) have been confirmed.

The length of posts also has an impact on likes and comments, but the effect is weak and both remain at a low level, which is consistent with the results of Sabate et al. (2014). At the same time, although there is little difference in the credibility of the corresponding association rules for posts with different character numbers to stimulate likes and comments, the credibility of L1, that is, shorter brand posts, is slightly higher than that of L2. This is similar to the survey results of Buddy Media Inc. in 2011, who claims that posts shorter than 80 characters are highly engaged.

The management implication from this discussion is as follows:

M2c: Brand page managers of Sina Weibo should use concise brand posts as far as possible to increase the possibility of engagement. The best effect is to keep the number of characters in the range of 16-50.

\section{Posting Time}

Regarding the potential influence of posting time on consumer engagement in brand posts, the results of this study are limited.

Taking sharing and liking into account, brand posts published on weekends affect consumer engagement more than workdays, which is consistent with the research results of Antoniadis et al. (2019). From the perspective of comments, brand posts published on weekends or workdays do not affect engagement. Although it is comparable to the research of Cvijikj and Michahelles (2013), this confirms the research results of Schultz (2017).

As the hypotheses in this paper are not fully confirmed, the paper could only suggest the following:

M3a: Brand page managers of Sina Weibo should release posts on weekends to increase the number of shares and likes.

Brand posts published during peak hours or low hours could not influence commenting or liking, which verifies the findings of Antoniadis (2019). In addition, the release time of brand posts stimulates the same level of sharing, but the confidence level of association rules generated in the low peak period is higher than that in the peak period. This is consistent with the research of Cvijikj and Michahelles (2013). A possible explanation may be that during peak hours, consumers pay more attention to communicating and maintaining relationships with friends than to motivations for the usage of social media (Raacke et al., 2008).

In summary, the management implication derived from the results obtained is as follows:

M3b: Brand page managers of Sina Weibo should post in the low peak period to improve consumer engagement through sharing.

\section{Conclusion, Limitations, and Future Work}

Brands deeply recognize the important role of social media as a marketing tool, but the interactive characteristics of social media change consumers from passive observers to active participants, which increase the difficulty of brand exploration and the discernment of characteristics that could promote consumer engagement. To improve the brand's understanding of social media consumer engagement, a conceptual framework of brand post content, form and posting time is constructed. Based on Sina Weibo, the RS method is used to explore the relationship and intensity of different brand post characteristics on consumer engagement.

Regarding post content, entertainment content stimulates a moderate level of consumer engagement, information content has a stronger effect on shares than comments and likes, and promotional content mainly promotes consumer engagement through likes. In terms of vividness, although pictures only affect the number of shares, they have the potential to encourage medium-level comments and likes. As the most attractive and vivid characteristic, videos significantly affect engagement at the middle-level. Regarding interactivity, pure text and calls to act stimulate moderate consumer engagement through sharing and liking, respectively. Questioning has a significant effect on consumer engagement at three levels. Links, whether representing vividness or interactivity, are more likely to stimulate lower engagement. In addition, brand page managers should try to keep the number of characters in the range of $16-50$ to increase the possibility of consumer engagement. As far as the posting time is concerned, the post created on weekend promotes the medium level of sharing and the low level of liking, while published in the peak or low period stimulates the same level of sharing. Based on different marketing purposes, brands should use different elements and design different content to promote consumer engagement and enhance intimacy with consumers. 
The paper responds to Munoz et al.'s (2018) call for expanding new methods, and the RS method is adopted to study the relationship between social media brand post characteristics and consumer engagement. The number of shares, comments and likes with different proportions of cognitive and emotional resource input is used to measure consumer engagement, which is discretized into three levels, corresponding to high, medium and low levels of consumer engagement. The characteristic reduction algorithm of Holte $1 \mathrm{R}$ is used to automatically generate decision rules with optimal results. RS not only studies the relationship between brand post characteristics and consumer engagement more objectively but also quantifies consumer engagement, and further discusses the difference of different brand post characteristics on consumer engagement in the effect intensity. The results of this study confirm the feasibility and effectiveness of the RS method in solving the problem of consumer engagement.

This study is expected to provide a meaningful theoretical reference for academic researchers. First, the study finds that the effects of post characteristics vary for different dimensions of consumer engagement (Tsai \& Men, 2013; Schultz, 2017). Second, a new perspective called brand post form is introduced by this study, which combines brand post content and posting time, effectively summarizes brand post characteristics, and constructs the conceptual framework of consumer engagement. It not only provides a reference for multiangle research on consumer engagement but also contributes to identifying and testing the characteristics that determine the success of brand post page construction. Finally, the paper is one of the first to use the RS method to explore the characteristics of consumer engagement. The RS method can analyse historical data without any prior knowledge, and capture the relationship between brand post characteristics and consumer engagement more intelligently. The results of association rules generated are also easy to understand and interpret. The effective application of the RS method in this field provides technical support for follow-up research and further broadens the research ideas of consumer engagement on social media.

This study is also expected to provide meaningful practical guidance for brand page managers. First, acknowledging the influence of the content, form and posting time of posts on consumer engagement is helpful to provide managers with a guide on what characteristics to add to brand posts. Second, enterprises and brands that use the brand page of Sina Weibo as a measure of social media marketing should continuously supervise their actions and consumers' interactions with them. New engagement strategies are formulated in real time by determining the changes in consumer engagement and brand post characteristics.

Although this study has certain theoretical and practical significance, there are limitations. First, the concept of engagement in this study is limited to online engagement, and its research results are limited to brand posts on the Sina Weibo platform. However, different social media platforms have different functions and mainstream user groups, which means that there are cultural differences between social media and the reasons behind consumer engagement are different. Future research is expected to study consumer engagement based on different platforms and further verify the applicability of the RS method in social media consumer engagement. Second, some potential variables that may affect consumer engagement are not included in the current variable list, such as the daily or monthly total number of fans on the Sina Weibo brand page. As the total number of fans grows, so does the number of fans who like, comment or share posts. Future research plans to investigate other characteristics that may affect engagement. Third, this paper focuses on active consumer engagement. However, not all brand activities have positive results (Adjei et al., 2016). To explain consumers' feelings about the content presented on the brand page as comprehensively as possible, future research is expected to explore the reasons behind the negative consumer engagement. Fourth, whether and in what form to engage in brand content may be caused by the combination of post characteristics affecting consumers as a whole, rather than the result of a single characteristic. RS could generate association rules involving multiple characteristics. Future research plans to use the RS method to further explore the impact of multiple characteristic combinations of brand posts on consumer engagement.

\section{Acknowledgement}

This research was supported by the Research and Planning Project of Philosophy and Social Sciences in Heilongjiang Province under Grant 20GLB115.

\section{References}

Adjei, M. T., Nowlin, E. L., \& Ang, T. (2016). The collateral damage of C2C communications on social networking sites: the moderating role of firm responsiveness and perceived fairness. Journal of Marketing Theory \& Practice, 24(2), 166-185. https://doi.org/10.1080/10696679.2016.1131057

Alves, H., Fernandes, C., \& Mario Raposo. (2016). Social media marketing: a literature review and implications: implications of social media marketing. Psychology and Marketing, 33(12), 1029-1038. https://doi.org/10.1002/mar.20936

Antoniadis, I., Paltsoglou, S., \& Patoulidis, V. (2019). Post popularity and reactions in retail brand pages on facebook. International Journal of Retail \& Distribution Management, (3). https://doi.org/10.1108/IJRDM-09-2018-0195

Asghar, M. Z., Khan, A., Khan, F., \& Kundi, F. M. (2017). Rift: a rule induction framework for twitter sentiment analysis. Arabian Journal for ence \& Engineering. https://doi.org/10.1007/s13369-017-2770-1

Ashley, C., \& Tuten, T. (2015). Creative strategies in social media marketing: an exploratory study of branded social content and consumer engagement. Psychology and Marketing, 32(1), 15-27. https://doi.org/10.1002/mar.20761 
Zhijie Zhao, Yang Liu, Jiaying Wang, Biao Wang, Yiqi Guo. Association Rules Analysis between Brand Post...

Azar, S. L., Machado, Joana Cesar, Vacas-De-Carvalho, L., \& Mendes, A. (2016). Motivations to interact with brands on facebook-towards a typology of consumer-brand interactions. Journal of Brand Management, 23(2), $153-178$. https://doi.org/10.1057/bm.2016.3

Baltas, G. (2003). Determinants of internet advertising effectiveness: an empirical study. International Journal of Market Research, 45(4). https://doi.org/10.1002/ijfe.198

Beukeboom, C. J., Kerkhof, P., \& de Vries, M., (2015). Does a virtual like cause actual liking? how following a Brand's Facebook updates enhances brand evaluations and purchase intention. J. Interact. Marketing 32, 26-36. https://doi.org/10.1016/j.intmar.2015.09.003

Brodie, R. J., Ilic, A., Juric, B., \& Hollebeek, L. (2013). Consumer engagement in a virtual brand community: An exploratory analysis. Journal of Business Research, 66(1), 105-114. https://doi.org/10.1016/j.jbusres.2011.07.029

Bronstein, \& Jenny. (2013). Like me! analyzing the 2012 presidential candidates' facebook pages. Online Information Review, 37(2), 173-192. https://doi.org/10.1108/OIR-01-2013-0002

Bruhn, M., Schoenmueller, V., \& DB Schafer. (2013). Are social media replacing traditional media in terms of brand equity creation?. Management Research Review, 35. https://doi.org/10.1108/01409171211255948

Busalim, A. H., Che Hussin, A. R., \& Iahad, N. A. (2019). Factors Influencing Customer Engagement in Social Commerce Websites: A Systematic Literature Review. Journal of Theoretical and Applied Electronic Commerce Research, 14(2), 114. https://doi.org/10.4067/S0718-18762019000200102

Chen, L. F., \& Tsai, C. T. (2016). Data mining framework based on rough set theory to improve location selection decisions: a case study of a restaurant chain. Tourism Management, 53(4), 197-206. https://doi.org/10.1016/j.tourman.2015.10.001

Cvijikj, I. P., \& Michahelles, F. (2013). Online engagement factors on facebook brand pages. Social Network Analysis\&Mining. https://doi.org/10.1007/s13278-013-0098-8

De Vries, L., Gensler, S., \& Leeflang, P. S. H. (2012). Popularity of brand posts on brand fan pages: an investigation of the effects of social media marketing. Journal of Interactive Marketing, 26(2), 83-91. https://doi.org/10.1016/ j.intmar.2012.01.003

De Vries, N. J., \& Carlson, J. (2014). Examining the drivers and brand performance implications of customer engagement with brands in the social media environment. Journal of Brand Management, 21(6), 495-515. https://doi.org/10.10 57/bm.2014.18

Delerue, H., Kaplan, A. M., \& Haenlein, M. (2013). Social media: back to the roots and back to the future. Journal of Systems \& Information Technology, 14(2), 148-59. https://doi.org/10.1108/13287261211232126

Ding, C. G., \& Tseng, T. H. (2015). On the relationships among brand experience, hedonic emotions, and brand equity. European Journal of Marketing, 49(7/8), 994-1015. https://doi.org/10.1108/EJM-04-2013-0200

Dolan, R. , Conduit, J., Fahy, J., \& Goodman, S. (2016). Social media engagement behaviour: A uses and gratifications perspective. Journal of Strategic Marketing, 24(3/4), 261-277. https://doi.org/10.1080/0965254X.2015.1095222

Dolan, R., J Conduit, Frethey-Bentham, C., J Fahy, \& Goodman, S. (2019). Social media engagement behavior: a framework for engaging customers through social media content. European Journal of Marketing. https://doi.org/10.1108/EJM-03-20170182

Dong, J. Q., \& Wu, W. (2015). Business value of social media technologies: evidence from online user innovation communities. Journal of Strategic Information Systems, 24(2), 113-127. https://doi.org/10.1016/j.jsis.2015.04.003

Gavilanes, J. M., Flatten, T. C., \& Brettel, M. (2018). Content strategies for digital consumer engagement in social networks: why advertising is an antecedent of engagement. Journal of Advertising, 47(1), 1-20. https://doi.org/10.1080/009133 67.2017.1405751

Gensler, S., Volckner, F., Liu-Thompkins, Y., \& Wiertz, C. (2013). Managing brands in the social media environment. Journal of Interactive Marketing, 27(4), 242-256. https://doi.org/10.1016/j.intmar.2013.09.004

Glaser, B. G., \& Strauss, A. L. (1967). The discovery of grounded theory: strategies for qualitative research. Social Forces, 46(4). https://doi.org/10.2307/2575405

Goh, K. Y., Heng, C. S., \& Lin, Z. (2013). Social media brand community and consumer behavior: quantifying the relative impact of user- and marketer-generated content. Information Systems Research, 24(1), 88-107. https://doi.org/10.1287/ isre. 1120.0469

Golder, S. A., Wilkinson, D. M., \& Huberman, B. A. (2007). Rhythms of social interaction: messaging within a massive online network. https://doi.org/10.1007/978-1-84628-905-7_3

Habibi, M. R., Laroche, M., \& Richard, M. O. (2014). Brand communities based in social media: how unique are they? evidence from two exemplary brand communities. International Journal of Information Management, 34(2), $123-132$. https://doi.org/10.1016/j.ijinfomgt.2013.11.010

Hollebeek, L. D., Glynn, M. S., \& Brodie, R. J. (2014). Consumer brand engagement in social media: conceptualization, scale development and validation. Journal of Interactive Marketing, 28(2), 149-165. https://doi.org/10.1016/j.intmar.2013. 12.002 
Holte, R. C. (1993). Very simple classification rules perform well on most commonly used datasets. Machine Learning, 11(1), 63-90. https://doi.org/10.1023/A:1022631118932

Hong, M. L. (2011). User Motivations for Using Business facebook Pages. Master's thesis. Retrieved from. http://scholarworks.boisestate.edu/td/223/

Islam, J. U., Rahman, Z., \& Hollebeek, L. D. (2018). Consumer engagement in online brand communities: a solicitation of congruity theory. Internet Research. https://doi.org/10.1108/intr-09-2016-0279

Ismail, A. R. (2017). The influence of perceived social media marketing activities on brand loyalty: the mediation effect of brand and value consciousness. Asia Pacific Journal of Marketing \& Logistics, 29(1), 1-17. https://doi.org/10.1108/APJML-102015-0154

Jaakonmaki, R., Muller, O., \& Brocke, J. V. (2017). The Impact of Content, Context, and Creator on User Engagement in Social Media Marketing. Hawaii International Conference on System Sciences, HICSS-50. https://doi.org/10.24251/ HICSS.2017.136

Jeon, H., \& Ahn, H. J. (2015). Identification of the factors that affect the user reaction to posts on facebook brand pages. IEEE, 203-206. https://doi.org/10.1109/ICCACS.2015.7361350

Kang, J., Tang, L., \& Fiore, A. M. (2014). Enhancing consumer-brand relationships on restaurant facebook fan pages: maximizing consumer benefits and increasing active participation. International Journal of Hospitality Management, 36, 145-155. https://doi.org/10.1016/j.ijhm.2013.08.015

Khan, I., Han, D., \& Wahab, A. (2016). Does culture matter in effectiveness of social media marketing strategy? an investigation of brand fan pages. Aslib Proceedings, 68(6), 694-715. https://doi.org/ 10.1108/AJIM-03-2016-0035

Khobzi, H., Lau, R. Y. K., \& Cheung, T. C. H. (2018). The outcome of online social interactions on facebook pages: a study of user engagement behavior. Internet Research. https:// doi.org/10.1108/IntR-04-2017-0161

Kim, C., \& Yang, S. U. (2017). Like, comment, and share on facebook: how each behavior differs from the other. Public Relations Review, S0363811116300157. https://doi.org/10.1016/j.pubrev.2017.02.006

Lee, D., Hosanagar, K., \& Nair, H. S. (2018). Advertising content and consumer engagement on social media: evidence from facebook. Social ence Electronic Publishing, 64(11). https://doi.org/10.1287/mnsc.2017.2902

Leeflang, P. S. H., Verhoef, P. C., Dahlstroem, P., \& Freundt, T. (2014). Challenges and solutions for marketing in a digital era. European Management Journal, 32(1), 1-12. https://doi.org/10.1016/j.emj.2013.12.001

Leung, X., Tanford, S., \& Jiang, L. (2017). Is a picture really worth a thousand words?: an experiment on hotel facebook message effectiveness. Journal of Hospitality and Tourism Technology, 8(1), 19-38. https://doi.org/10.1108/JHTT-082016-0039

Liangjun, Z., Tan, Y., Gang, X., \& Shengbing, X. (2015). MATLAB data analysis and mining practice. China Machine Press

Liu, Y., \& Shrum, L. J. (2002). What is interactivity and is it always such a good thing? implications of definition, person, and situation for the influence of interactivity on advertising effectiveness. Journal of Advertising, 31(4), 53-64. https://doi.org/10.1080/00913367.2002.10673685

Liu, Z., Liu, L., \& Li, H. (2012). Determinants of information retweeting in microblogging. Internet Research Electronic Networking Applications \& Policy, 22(4), 443-466(24). https://doi.org/10.1108/10662241211250980

Luarn, P., Lin, Y. F., \& Chiu, Y. P. (2015). Influence of facebook brand-page posts on online engagement. Online Information Review, 39(4), 505-519. https://doi.org/10.1108/OIR-01-2015-0029

Menon, R. G. V., Sigurdsson, V., Larsen, N. M., Fagerstrom, A., Sorensen, H., \& Marteinsdottir, H. G., et al. (2019). How to grow brand post engagement on facebook and twitter for airlines? an empirical investigation of design and content factors. Journal of Air Transport Management, 79(AUG.), 101678.1-101678.9. https://doi.org/10.1016/j.jairtraman.2019.05.002

Morra, M. C., Ceruti, F., Chierici, R., \& Di Gregorio, A. (2018), Social vs traditional media communication: brand origin associations strike a chord, Journal of Research in Interactive Marketing, 12(1), 2-21. https://doi.org/10.1108/jrim-122016-0116

Munoz, L., Liebana, L., \& Hernandez, M. (2018), Etourism advertising effectiveness: Banner type and engagement as moderators, Journal of Services Marketing, 32(4), 462-475. https://doi.org/10.1108/JSM-01-2017-0039

Muntinga, D. G., Moorman, M., \& Smit, E. G. (2011). Introducing cobras. International Journal of Advertising, 30 , $13-46$. https://doi.org/10.2501/IJA-30-1-013-046

Pawlak, Z., Grzymala-Busse, J., Slowinski, R., \& Ziarko, W. (1995). Rough sets. Communications of the ACM. https://doi.org/10.1145/219717.219791

Raacke, J., \& Bonds-Raacke, J. (2008). Myspace and facebook: applying the uses and gratifications theory to exploring friendnetworking sites. CyberPsychology \& Behavior, 11(2), 169-174. https://doi.org/10.1089/cpb.2007.0056

Rietveld, R., Van Dolen, W., Mazloom, M., \& Worring, M. (2020). What you feel, is what you like influence of message appeals on customer engagement on instagram. Journal of Interactive Marketing, 49. https://doi.org/10.1016/j.intmar.2019.06.003 
Zhijie Zhao, Yang Liu, Jiaying Wang, Biao Wang, Yiqi Guo. Association Rules Analysis between Brand Post...

Rishika, R., Kumar, A., Janakiraman, R., \& Bezawada, R. (2013). The effect of customers' social media participation on customer visit frequency and profitability: an empirical investigation. Information Systems Research, 24(1), $108-127$. https://doi.org/10.1287/isre.1120.0460

Sabate, F., Berbegal-Mirabent, J., Canabate, A., \& Lebherz, P. R. (2014). Factors influencing popularity of branded content in facebook fan pages. European Management Journal, 32(6), 1001-1011. https://doi.org/10.1016/j.emj.2014.05.001

Schultz, \& Carsten, D. (2017). Proposing to your fans: which brand post characteristics drive consumer engagement activities on social media brand pages?. Electronic Commerce Research and Applications, 26, 23-34. https://doi.org/10.101 6/j.elerap.2017.09.005

Shahbaznezhad, H., Dolan, R., \& Rashidirad, M. (2020). The role of social media content format and platform in users' engagement behavior. Journal of Interactive Marketing, 53(4). https://doi.org/10.1016/j.intmar.2020.05.001

Shi, S., Chen, Y., \& Chow, W. S. (2016). Key values driving continued interaction on brand pages in social media: an examination across genders. Computers in Human Behavior, 62(Sep.), 578-589. https://doi.org/10.1016/j.chb.2016.04.017

Shi, Z., Rui, H., \& Whinston, A. B. (2014). Content sharing in a social broadcasting environment. MIS Quarterly. https://doi.org/10.25300/MISQ/2014/38.1.06

Sina Weibo data center. (2019). https://data.weibo.com/report/reportDetail?id=433

Statista (2019). Active Social Network Penetration in Selected Countries as of January 2019. Available at: https://www.statista.com/statistics/282846/regular-social-networking-usage-penetration-worldwideby-country.

Stelios, B., Nikolaos, L., Nikolaos, M., \& Frank, B. (2018). Customer satisfaction prediction in the shipping industry with hybrid meta-heuristic approaches. Computational Economics. https://doi.org/10.1007/s10614-018-9842-5

Steuer, J. (1992). Defining virtual reality: dimensions determining telepresence. Journal of Communication. https://doi.org/10.1111/j.1460-2466.1992.tb00812.x

Susan, F. (1998). Consumers and their brands: developing relationship theory in consumer research. Journal of Consumer Research(4), 343-353. https://doi.org/10.1086/209515

Swani, K., \& Labrecque, L. I. (2020). Like, comment, or share? self-presentation vs. brand relationships as drivers of social media engagement choices. Marketing Letters, 31. https://doi.org/10.1007/s11002-020-09518-8.

Tafesse, W. (2015). Content strategies and audience response on Facebook brand pages. Marketing Intelligence \& Planning, 33(6), 927-943. https://doi.org/10.1108/MIP-07-2014-0135

Trefzger, T. F., Baccarella, C. V., \& Voigt, K. I. (2016). Antecedents of brand post popularity in Facebook: The influence of images, videos, and text. International Marketing Trends Conference.

Tsai, W. H. S., \& Men, L. R. (2013). Motivations and antecedents of consumer engagement with brand pages on social networking sites. Journal of Interactive Advertising, 13(2), 76-87. https://doi.org/10.1080/15252019.2013.826549

Villamediana, J., Kuster, I., \& Vila, N. (2019). Destination engagement on facebook: time and seasonality. Annals of tourism research, 79(Nov.), 102747.1-102747.16. https://doi.org/10.1016/j.annals.2019.102747

Vinterbo, S., \& OHrn, A. (1999). Minimal approximate hitting sets and rule templates. International Journal of Approximate Reasoning, 25(2), 123-143. https://doi.org/10.1016/S0888-613X(00)00051-7

Wang, X., Wen, Q., Dan, Z., Wang, N. A., Management, S. O., \& University, J. (2018). Research on online public opinion dissemination path and network structure of natural disaster in new media environment-a case study of the topic of "ya'an earthquake" in sina weibo. Journal of intelligence.

Xuecheng, Y., Bing, L., Fei, S., \& Management, S. O. (2015). How brand microblogging attract fans interaction?-an empirical study based on CMC theory. Management Review.

Zhang, H., Lu, Y., Gupta, S., \& Zhao, L. (2014). What motivates customers to participate in social commerce? the impact of technological environments and virtual customer experiences. Information \& Management, 51(8), $1017-1030$. https://doi.org/10.1016/j.im.2014.07.005

Zhang, M., Guo, L., Hu, M., \& Liu, W. (2017). Influence of customer engagement with company social networks on stickiness: mediating effect of customer value creation. International Journal of Information Management, 37(3), 229-240. https://doi.org/10.1016/j.ijinfomgt.2016.04.010

\section{Authors' biographies}

Zhijie Zhao received the B.S. and M.S. degrees from the Harbin University of Science and Technology, China, in 1985 and 1988, respectively, and the Ph.D. degree from the Harbin Institute of Technology in 2008. He is currently a Professor at the School of Computer and Information Engineering, Harbin University of Commerce, China. His research interests include image processing and intelligence information processing.

Yang Liu is currently pursuing a Ph.D. degree in e-commerce from the School of Computer and Information Engineering, Harbin University of Commerce, China. Her research interests include the cross-application of big data technology in the field of e-commerce, consumer engagement behavior, and social media. 
Jiaying Wang is a Ph.D. candidate in the Department of Computer and Information Engineering, Harbin University of Commerce, and a lecturer of Zaozhuang University, Harbin, China. His research interests include consumer behavior, electronic word-of-mouth (eWOM), e-commerce, and social media.

Biao Wang received a B.S from the Shanxi University of Finance and Economics, China, in 1986, and M.S. degrees from the Jilin University, China, in 2001. He is currently a Professor at the Business School, Harbin University of Commerce, China. His research interests include statistics and quantitative economic analysis.

Yiqi Guo is a master candidate in electronic commerce in the School of Computer and Information Engineering of Harbin University of Commerce, China. Her research interests include consumer behavior and social media.

The article has been reviewed.

Received in November 2020; accepted in October 2021. 